\title{
Sistem pengelolaan laboratorium pengujian bahan untuk mewujudkan pelaksanaan praktikum yang efisien
}

\author{
Zuraida $^{1^{\star}}$, Robby Cahyadi ${ }^{2}$ \\ 1,2Politeknik Negeri Banjarmasin \\ Jl. Brig Jend. Hasan Basri, Pangeran, Kec. Banjarmasin Utara, Kota Banjarmasin, \\ Kalimantan Selatan 70124 \\ *Corresponding author: zuraidaachmad81@gmail.com
}

\begin{abstract}
Abstrak
Permasalahan yang dihadapi Laboratorium Pengujian Bahan di Politeknik Negeri Banjarmasin adalah: sumber daya manuasia (SDM) kurang kompeten, kepala laboratorium bukan sebagai pekerjaan utama, laboratorium belum dikelola dengan baik, serta laboratorium belum dapat dimanfaatkan secara optimal. Untuk mengatasi masalah tersebut maka dilakukan bimbingan teknis tenaga laboratorium, dan workshop manajemen laboratorium. Tahapan yang dilakukan meliputi: pembinaan teknis SDM, workshop pengelolaan laboratorium, inventarisasi dan pelabelan, workshop penyusunan jadwal, standard operating procedure (SOP), dan implementasinya. Hasil yang diperoleh adalah Laboratorium Pengujian Bahan di Politeknik Negeri Banjarmasin secara umum telah memenuhi standar sarana dan prasarana, SDM yang kurang, manajemen yang baik dapat membantu praktikum berjalan secara efisien sesuai jadwal.
\end{abstract}

Kata kunci: sistem manajemen laboratorium, Laboratorium Pengujian Bahan, dan efisiensi.

\section{Pendahuluan}

Pemerintah telah menetapkan delapan standar pendidikan melalui PP RI No. 19 Tahun 2005 yang meliputi standar isi, standar proses, standar kompetensi lulusan, standar pendidik dan kependidikan, standar sarana dan prasarana, standar pengelolaan, standar pembiayaan dan standar penilaian [1]. Berdasarkan Permendiknas Nomor 24 Tahun 2007, Laboratorium adalah salah satu standar sarana dan prasarana yang harus dipenuhi oleh setiap satuan pendidikan formal [2]. Karena itu melalui berbagai program pemerintah telah berupaya memenuhi kebutuhan laboratorium mulai dari pengadaan gedung, prasarana, peralatan, dan bahan laboratorium serta penyiapan sumberdaya manusia melalui pelatihan-pelatihan terhadap para laboran tentang pengelolaan laboratorium. Namun demikian sangat disayangkan hasil-hasil pelatihan tersebut jarang diimplementasikan $[3,4]$.

Setiap Laboratorium terbentuk tata kelola, yakni terdiri dari 1 orang Kepala
Laboratorium dan 1 orang fungsional laboran [5]. Beberapa kendala dan masalah dalam pengelolaan laboratorium adalah:

1) Kepala laboratorium hanya sebagai profesi sampingan,

2) Laboran belum menguasai dan memahami berbagai alat laboratorium dan pekerjaan laboran,

3) Minat dan motivasi penggunaan laboratorium dalam pembelajaran kurang,

4) Laboratorium tidak dikelola dengan baik, sehingga jika ingin menggunakan laboratorium harus menyiapkan sendiri mulai dari perencanaan, penyiapan alat, penggunaan dan pengembalian serta penyimpanan alat,

5) Alat dan bahan laboratorium belum tersusun dengan baik, sehingga untuk mencari satu jenis alat saja diperlukan waktu dan curah tenaga yang cukup banyak,

6) Ruang laboratorium sering digunakan untuk kegiatan lain, seperti rapat- 
rapat, atau bahkan sebagai ruang untuk penyimpanan berbagai barang lainnya.

Sehingga diperlukan program peningkatan sumberdaya manusia yang menguasai manajemen dan sistem pengelolaan laboratorium. Selain pengetahuan yang cukup, juga perlu adanya motivasi dan dorongan yang kuat agar para pengelola laboratorium mampu dan mau mengimplementasikan pengetahuannya dalam membangun sistem pengelolaan laboratorium yang efektif dan efisien. Dengan demikian, maka perlu dilakukan treatment untuk memfasilitasi implementasi sistem pengelolaan laboratorium tersebut [5].

Banyak program pelatihan yang diikuti oleh pendidik maupun tenaga kependidikan tidak terimplementasi. Hal ini disebabkan oleh beberapa aspek, antara lain: aspek individu peserta diklat yang tidak memiliki niat dan motivasi untuk bekerja lebih baik, aspek manajemen sekolah yang kurang memfasilitasi penerapan hasil diklat, serta aspek materi diklat yang terkadang tidak didasarkan atas kebutuhan $[4,6]$.

Karena itu, perlu program bimtek tenaga laboratorium yang dilanjutkan dengan pendampingan dalam pengelolaan dan pemberdayaan laboratorium serta pembuatan SOP berbagai kegiatan laboratorium. Dengan demikian, maka peranan laboratorium dalam menunjang proses pembelajaran dapat dioptimalkan dan kegiatan praktikum dapat berjalan secara efisien [7].

Berdasarkan beberapa pendapat di atas, maka peran laboratorium sangat penting dalam mendukung proses pembelajaran. Sehingga perlu diupayakan pengembangan dan penerapan manajemen dan administrasi yang baik agar laboratorium dapat digunakan lebih mudah dalam mendukung proses pembelajaran. Menurut Suseno, dkk. (2014) dalam administrasi laboratorium terdapat enam jenis data inventaris, yaitu format A (denah dan data ruang), format B (data barang), format $\mathrm{C}$ (data alat), format $\mathrm{D}$ (data bahan), format $\mathrm{E}$ (data ketenagaan) dan format $\mathrm{F}$ (agenda kegiatan laboratorium) [6].

Berdasarkan uraian di atas, maka perlu dilakukan upaya untuk mengoptimalkan penggunaan laboratorium pengujian bahan, melalui pembenahan manajemen laboratorium dan administrasi yang baik, terutama dalam inventaris alat dan bahan laboratorium untuk mempermudah penggunaan laboratorium dalam mendukung proses pembelajaran melalui kegiatan praktikum.

\section{Metode Penelitian}

Guna memberdayakan laboratorium pengujian bahan, maka dilakukan suatu treatment (perlakuan) berupa bimbingan teknis (bimtek) tenaga laboratorium dan pendampingan dalam pengelolaan laboratorium. Program tersebut dilaksanakan di Politeknik Negeri Banjarmasin. Program ini meliputi tiga tahap, yaitu:

1. Tahap pertama, dilakukan Bimtek tenaga laboratorium yang meliputi aspek managemen, administrasi alat dan bahan praktikum, serta penyusunan program praktikum (telah dilakukan sebelumnya).

2. Tahap kedua, workshop dan pendampingan dalam menyusun manual pengelolaan laboratorium, melakukan inventaris alat dan bahan secara online dan beberapa standar operasional prosedur (SOP) kegiatan laboratorium,

3. Tahap ketiga dilakukan uji coba penggunaan laboratorium berdasarkan SOP yang telah dikembangkan pada tahap kedua.

Untuk mengetahui dampak dari Bimtek dan pendampingan dalam pemberdayaan laboratorium, maka dilakukan pengumpulan data sebelum dan sesudah perlakuan. Pengumpulan data dilakukan melalui observasi, wawancara dan dokumentasi. Data tersebut kemudian diolah dan dianalisis dengan cara membandingkan kondisi sebelum dan 
sesudah diberi perlakuan baik secara kuantitatif maupun kualitatif.

\section{Hasil dan Pembahasan}

Beberapa permasalahan mendasar dari laboratorium pengujian bahan:

1) Tenaga laboratorium yang bukan dari pendidikan khusus laboran,

2) tenaga laboratorium yang ada belum menguasai prinsip dan konsep pengelolaan laboratorium,

3) Alat dan bahan laboratorium belum tersusun baik dan data inventaris yang dimiliki belum lengkap dan tidak terdokumentasi dengan baik,

4) belum memiliki manual pengelolaan laboratorium dan belum memiliki standar operasional prosedur (SOP) dalam pelayanan laboratorium,

5) program kerja yang telah dibuat sebagian besar tidak terlaksana, 6) Laboratorium belum digunakan secara maksimal dalam mendukung proses pembelajaran.

Hasil survei menemukan beberapa kendala dan masalah dalam pengelolaan laboratorium tersebut, yaitu:

1) Kepala laboratorium hanya sebagai profesi sampingan,

2) Tidak ada laboran yang mampu menguasai dan memahami berbagai alat laboratorium dan pekerjaan laboran,

3) Minat dan motivasi untuk menggunakan laboratorium dalam pembelajaran kurang,

4) Laboratorium tidak dikelola dengan baik, sehingga jika ingin menggunakan laboratorium harus menyiapkan sendiri mulai dari perencanaan, penyiapan alat, penggunaan dan pengembalian serta penyimpanan alat,

5) Alat-alat laboratorium belum tersusun dengan baik, sehingga untuk mencari satu jenis alat saja diperlukan waktu dan curah tenaga yang cukup banyak,

6) Ruang laboratorium sering digunakan untuk kegiatan lain, seperti rapatrapat, atau bahkan sebagai ruang untuk penyimpanan berbagai barang lainnya (berfungsi sebagai gudang).

1. Program Kegiatan dan Target

Berdasarkan hasil studi

pendahuluan, maka disusun suatu buku panduan bagi kepala laboratorium yang kemudian digunakan sebagai bahan ajar dalam kegiatan bimtek kepala laboratorium. Setelah dilakukan bimtek bagi tenaga laboratorium, kemudian dilanjutkan pendampingan untuk mengimplementasikan teori dan prinsip pengelolaan Laboratorium yang telah dibekalkan kepada Tenaga laboratorium tersebut. Beberapa ketercapaian target tersebut diuraikan pada Tabel 1.

Tabel 1. Kegiatan bimtek tenaga lab, pendampingan, capaian target.

\begin{tabular}{|c|c|c|c|c|}
\hline $\begin{array}{l}\mathbf{N} \\
\mathbf{0}\end{array}$ & Kegiatan & Sasaran & Target & $\begin{array}{l}\text { Data } \\
\text { hasil }\end{array}$ \\
\hline 1 & $\begin{array}{l}\text { Bimek } \\
\text { tenaga lab }\end{array}$ & $\begin{array}{l}\text { Kepala } \\
\text { lab \& \& } \\
\text { laboran }\end{array}$ & $\begin{array}{l}\text { Tenaga } \\
\text { laboratoriu } \\
\mathrm{m} \\
\text { menguasai } \\
\text { konsep, } \\
\text { pronsip, } \\
\text { dan teknik } \\
\text { pengelolaa } \\
\mathrm{n} \text { lab. }\end{array}$ & $\begin{array}{l}\text { Nilai test } \\
\text { skala } 100 \\
\text { Nilai pre- } \\
\text { test } 64 \\
\text { Nilai } \\
\text { post-test } \\
77\end{array}$ \\
\hline 2 & $\begin{array}{l}\text { Worksho } \\
\mathrm{p} \\
\text { penyusun } \\
\text { an manual } \\
\text { pengelola } \\
\text { an lab. }\end{array}$ & $\begin{array}{l}\text { Kepala } \\
\text { lab \& \& } \\
\text { laboran }\end{array}$ & $\begin{array}{l}\text { Tersusun } \\
\text { manual } \\
\text { pengelolaa } \\
\text { n lab }\end{array}$ & $\begin{array}{l}\text { Manual } \\
\text { pengelola } \\
\text { an lab }\end{array}$ \\
\hline 3 & $\begin{array}{l}\text { Melakuka } \\
\mathrm{n} \\
\text { inventaris } \\
\text {, labeling } \\
\text { dan } \\
\text { penyusun } \\
\text { an alat } \\
\text { dan bahan } \\
\text { lab }\end{array}$ & Laboran & $\begin{array}{l}\text { Sarana dan } \\
\text { prasarana } \\
\text { lab }\end{array}$ & $\begin{array}{l}\text { Data } \\
\text { inventaris } \\
\text { lab berupa } \\
\text { jumlah } \\
\text { dan } \\
\text { kondisi }\end{array}$ \\
\hline 4 & $\begin{array}{l}\text { Pembuata } \\
\text { n program } \\
\text { kerja lab }\end{array}$ & $\begin{array}{l}\text { Kepala } \\
\text { lab \& \& } \\
\text { laboran }\end{array}$ & $\begin{array}{l}\text { Terbentuk } \\
\text { program } \\
\text { kerja } \\
\text { semester } \\
\text { dan } \\
\text { tahunan }\end{array}$ & $\begin{array}{l}\text { Program } \\
\text { kerja } \\
\text { semester } \\
\text { dan } \\
\text { tahunan } \\
\text { terwujud }\end{array}$ \\
\hline 5 & $\begin{array}{l}\text { Uji coba } \\
\text { pengguna } \\
\text { an lab }\end{array}$ & $\begin{array}{l}\text { Kepala } \\
\text { lab, } \\
\text { laboran, } \\
\text { mahasis } \\
\text { wa }\end{array}$ & $\begin{array}{l}\text { Kegiatan } \\
\text { praktikum } \\
\text { di lab } \\
\text { terlaksana } \\
\text { sesuai } \\
\text { jadwal }\end{array}$ & $\begin{array}{l}\text { Dihasilka } \\
\mathrm{n} \\
\text { dokumen: } \\
\text { SOP } \\
\text { praktikum } \\
\text { jadwal } \\
\text { kegiatan, } \\
\text { dan tata } \\
\text { tertib }\end{array}$ \\
\hline
\end{tabular}


Berdasarkan Tabel 1, maka dapat dikemukakan bahwa setelah dilakukan bimtek bagi tenaga laboratorium, pengetahuan tenaga laboratorium meningkat sebesar 34,1\%. Kemudian setelah dilakukan pendampingan, maka diperoleh beberapa produk yaitu:

1) Manual pengelolaan laboratorium,

2) Daftar inventaris alat dan bahan laboratorium yang memuat informasi tentang jenis, jumlah, kondisi dan tempat penyimpanannya,

3) Program kerja semester dan tahunan yang sesuai dengan kondisi dan kebutuhan mahasiswa.

2. Hasil Uji Coba Penggunaan Lab dalam Pelaksanaan Praktikum

Setelah administrasi dan manajemen laboratorium dibenahi, maka selanjutnya dilakukan uji coba pelaksanaan praktikum sesuai dengan jadwal. Dalam uji coba ini dilihat efektivitas dan efisiensi penyelenggaraan praktikum sesuai jadwal setelah dilakukan pembenahan administrasi dan manajeman laboratorium, serta daftar inventaris alat dan bahan laboratorium telah dibenahi. Hasil uji coba diungkapkan pada Tabel 2.

Tabel 2. Data hasil uji coba pelaksanaan praktikum

\begin{tabular}{|c|c|c|c|c|c|}
\hline No & $\begin{array}{c}\text { Aspek } \\
\text { pengamatan }\end{array}$ & $\begin{array}{c}\text { Uji } \\
\text { coba } 1\end{array}$ & $\begin{array}{c}\text { Uji } \\
\text { coba } \\
2\end{array}$ & $\begin{array}{c}\mathbf{U j i} \\
\text { coba } \\
\mathbf{3}\end{array}$ & $\begin{array}{c}\text { Rata- } \\
\text { rata }\end{array}$ \\
\hline 1 & $\begin{array}{l}\text { Penyiapan } \\
\text { alat } \\
\text { praktikum }\end{array}$ & $\begin{array}{l}22 \\
\text { menit }\end{array}$ & $\begin{array}{l}20 \\
\text { menit }\end{array}$ & $\begin{array}{l}18 \\
\text { menit }\end{array}$ & $\begin{array}{l}20 \\
\text { menit }\end{array}$ \\
\hline 2 & $\begin{array}{l}\text { Jarak ruang } \\
\text { kuliah ke lab }\end{array}$ & $20 \mathrm{~m}$ & $21 \mathrm{~m}$ & $22 \mathrm{~m}$ & $21 \mathrm{~m}$ \\
\hline 3 & $\begin{array}{l}\text { Alokasi } \\
\text { waktu } \\
\text { perkuliahan }\end{array}$ & $\begin{array}{l}2 \text { sks } \\
\text { (90 } \\
\text { menit) }\end{array}$ & $\begin{array}{l}2 \text { sks } \\
(90 \\
\text { menit) }\end{array}$ & $\begin{array}{l}2 \text { sks } \\
(90 \\
\text { menit) }\end{array}$ & $\begin{array}{l}2 \text { sks } \\
(90 \\
\text { menit) }\end{array}$ \\
\hline 4 & $\begin{array}{l}\text { Pembukaan di } \\
\text { ruang kuliah }\end{array}$ & $\begin{array}{l}15 \\
\text { menit }\end{array}$ & $\begin{array}{l}16 \\
\text { menit }\end{array}$ & $\begin{array}{l}15 \\
\text { menit }\end{array}$ & $\begin{array}{l}15,3 \\
\text { menit }\end{array}$ \\
\hline 5 & $\begin{array}{l}\text { Waktu } \\
\text { mahasiswa } \\
\text { pindah dari } \\
\text { ruang kuliah } \\
\text { ke lab }\end{array}$ & 4 menit & $\begin{array}{l}4 \\
\text { menit }\end{array}$ & $\begin{array}{l}5 \\
\text { menit }\end{array}$ & $\begin{array}{l}4,3 \\
\text { menit }\end{array}$ \\
\hline 6 & $\begin{array}{l}\text { Kegiatan } \\
\text { praktikum }\end{array}$ & $\begin{array}{l}70 \\
\text { menit }\end{array}$ & $\begin{array}{l}72 \\
\text { menit }\end{array}$ & $\begin{array}{l}69 \\
\text { menit }\end{array}$ & $\begin{array}{l}70,3 \\
\text { menit }\end{array}$ \\
\hline 7 & $\begin{array}{l}\text { Kembali ke } \\
\text { ruang kuliah } \\
\text { dari lab }\end{array}$ & 5 menit & $\begin{array}{l}5 \\
\text { menit }\end{array}$ & $\begin{array}{l}4 \\
\text { menit }\end{array}$ & $\begin{array}{l}4,6 \\
\text { menit }\end{array}$ \\
\hline 8 & $\begin{array}{l}\text { Total } \\
\text { kelebihan } \\
\text { waktu }\end{array}$ & 4 menit & $\begin{array}{l}7 \\
\text { menit }\end{array}$ & $\begin{array}{l}3 \\
\text { menit }\end{array}$ & $\begin{array}{l}4,6 \\
\text { menit }\end{array}$ \\
\hline 9 & $\begin{array}{l}\text { Waktu } \\
\text { perapihan alat }\end{array}$ & $\begin{array}{l}10 \\
\text { menit }\end{array}$ & $\begin{array}{l}8 \\
\text { menit }\end{array}$ & $\begin{array}{l}12 \\
\text { menit }\end{array}$ & $\begin{array}{l}10 \\
\text { menit }\end{array}$ \\
\hline
\end{tabular}

Berdasarkan hasil uji coba penggunaan laboratorium yang dikemukakan pada Tabel 2, dapat dikemukakan bahwa pelaksanaan praktikum sesuai jadwal dan tidak mengganggu mata kuliah lain, karena dari jadwal yang disediakan pada mata kuliah pengujian bahan yang perkuliahannya menggunakan metode praktikum di laboratorium hanya berlebih 4,6 menit. Selain itu waktu perpindahan ke laboratorium atau sebaliknya rata-rata hanya memerlukan waktu 4,6 menit.

Berdasarkan Tabel 2 juga dapat dikemukakan bahwa persiapan alat praktikum memerlukan waktu rata-rata 20 menit, sedangkan waktu perapihan alat praktikum hanya memerlukan waktu ratarata 10 menit. Hal ini menunjukan bahwa setelah manajemen dan administrasi laboratorium dibenahi melalui bimtek dan pendampingan dalam pengelolaan laboratorium, maka laboratorium pengujian bahan di kampus Politeknik Negeri Banjarmasin dapat dimanfaatkan dalam menunjang proses perkuliahan Pengujian Bahan secara efektif dan efisien, sehingga memudahkan dosen dan mahasiswa dalam kegiatan praktikum.

\section{Kesimpulan}

Berdasarkan hasil dan pembahasan yang telah dikemukakan di atas, maka dapat dikemukakan beberapa kesimpulan:

1. Secara umum kondisi laboratorium Pengujian Bahan di Politeknik Negeri Banjarmasin telah memenuhi standar sarana prasarana laboratorium,

2. Keadaan laboratorium yang tidak memenuhi standar adalah pada aspek tenaga teknisi,

3. Laboratorium Pengujian Bahan di Politeknik Negeri Banjarmasin dapat dimanfaatkan dalam menunjang proses perkuliahan Pengujian Bahan secara efektif dan efisien, setelah manajemen dan administrasi laboratorium dibenahi, sehingga memudahkan dosen dan mahasiswa dalam kegiatan praktikum. 


\section{Referensi}

[1] Kemendiknas, 2005. Peraturan Pemerintah Republik Indonesia Nomor 19 Tahun 2005 tentang Standar Pendidikan.

[2] Kemendiknas, 2007. Peraturan Menteri Pendidikan Nasional Republik Indonesia Nomor 24 Tahun 2007 tentang Standar Sarana prasarana Sekolah Dasar/Madrasah Ibtidaiyah (SD/MI), Sekolah Menengah Pertama/Madrasah Tsanawiyah (SMA/MTs) dan Sekolah Menengah Atas/ Madrasah Aliyah (SMA/MA).

[3] Novianti, N.R. 2011. Kontribusi Pengelolaan Laboratorium dan Motivasi Belajar Siswa terhadap Efektivitas Proses Pembelajaran. Jurnal Pendidikan MIPA. Edisi khusus. No. 1, halaman: $158-166$.

[4] Suseno, Nyoto, Partono \& Purwiro Harjati. 2011.Memadukan Alat Peraga dan Analogi Sebagai Upaya Menerapkan Inkuiri dalam Pembelajaran Konsep Abstrak Fisika. Jurnal Nuansa Pendidikan, Vol. 15 No. 1, halaman: 1-8.

[5] Suseno, Nyoto. 2012. Peran Praktikum dalam Mengembangkan Kemampuan dan Karakter Mahasiswa Calon Guru Fisika. Metro: Prosiding Seminar Nasional ke-1 UM Metro 2012. Tim Lesson Studi FKIP UM Metro, halaman 132139.

[6] Suseno, Nyoto, dkk. 2014. Buku Panduan Kepala Laboratorium Sekolah/Madrasah. Lembaga Penelitian UM Metro Press. Kota Metro.

[7] Yolanda, Berti, Tapillow, Fransisca S. \& Wulan, Anaratna. Implementasi Pembelajaran Berbasis Praktikum pada Pembelajaran Konsep Metabolisme untuk Meningkatkan Kemampuan Berpikir Kritis. Jurnal Pendidikan MIPA, Vol. 12 No. 1, halaman: 59 - 66. 